\title{
Ipseidad y estructura dialógica en la filosofía de Karl-Otto Apel ${ }^{*}$
}

Nicolás Perrone $e^{* *}$

Recibido: 27 de abril de 2016 - Aprobado: 7 de julio de 2016

R

El presente artículo aborda el problema de la identidad y la otredad en la filosofía de Karl-Otto Apel, teniendo en cuenta que la estructura dialógica de la racionalidad permite pensar más allá de la filosofía tradicional de la conciencia. Según este objetivo, se emplean las categorías de ipseidad y mismidad, propuestas por Paul Ricoeur, a modo de instrumento metodológico, para realizar una lectura de la obra de Apel respecto al problema planteado. Así, el posicionamiento de Apel con relación a la dialogicidad y a la intersubjetividad pone de manifiesto la importancia de la argumentación colectiva en la configuración de una identidad a modo de ipseidad.

Palabras clave: ipseidad, otredad, dialogicidad, intersubjetividad, Apel.

Artículo de reflexión, fruto de una investigación realizada en el marco del proyecto Reconocimiento y diversidad Para un humanismo crítico de América Latina en el siglo XX (FFyL, UNCuyo). DOI: http://dx.doi.org/10.15332/ s0120-8454.2017.0090.06

* Profesor de grado universitario en Filosofía. Universidad Nacional de Cuyo, Mendoza, Argentina. J.V.Zapata 481 ${ }^{\circ} \mathrm{D}$ Ciudad, Mendoza, CP: 5500. Email: luisnicolasperrone@gmail.com 


\section{Ipseity and dialogical structure in Karl-Otto Apel's philosophy*}

Nicolás Perrone ${ }^{* *}$

\section{A bstract}

This paper is about the problem of identity and otherness in Karl-Otto Apel's philosophy, considering that the dialogical structure of rationality allows thinking beyond the traditional philosophy of conscience. As a methodological tool, the categories of ipseity and selfhood, proposed by Paul Ricoeur, are used in order to develop a reading of Apel's work regarding identity and otherness. Consequently, Apel's positioning in relation to dialogicity and intersubjectivity highlights the importance of the collective argument in shaping an identity as ipseity.

Keywords: Ipseity, otherness, dialogicity, intersubjectivity, Apel.

Reflection article, result of a research carried out within the framework of the Recognition and Diversity project. For a critical humanism in Latin America in the Twentieth Century (FFyL, UNCuyo). DOI: http://dx.doi.org/10.15332/ s0120-8454.2017.0090.06

"* Undergraduate professor in Philosophy. National University of Cuyo, Mendoza, Argentina. J.V.Zapata $481^{\circ} \mathrm{D}$ Ciudad, Mendoza, CP: 5500. Email: luisnicolasperrone@gmail.com 


\section{Ipséité et structure dialogique dans la philosophie de Karl-Otto Apel*}

Nicolás Perrone $e^{* *}$

\section{Résumé}

Cet article aborde le problème de l'identité et de l'altérité dans la philosophie de Karl-Otto Apel, en tenant compte que la structure dialogique de la rationalité nous permet de penser au-delà de la philosophie traditionnelle de la conscience. Selon cet objectif, on emploi les catégories d'ipséité et mêmeté, proposées par Paul Ricoeur, comme instrument méthodologique pour réaliser une lecture de l'œuvre d d'Apel face au problème posé. Ainsi, le point de vue d'Apel par rapport à la dialogique et à l'intersubjectivité met en évidence l'importance de l'argumentation collective dans l'élaboration d'une identité à titre d'ipséité.

Mots clés: Ipséité, altérité, dialogique, intersubjectivité, Apel.

Article de réflexion, recherche réalisée dans le cadre du projet Reconnaissance et diversité, para un humaniste critique de I'Amérique Latine au XX siècle (FFyL, UNCuyo). DOI: http://dx.doi.org/10.15332/s0120-8454.2017.0090.06

Professeur universitaire de Philosophie. Université Nationale de Cuyo. Mendoza, Argentina. J.V.Zapata $481^{\circ} \mathrm{D}$ Ciudad, Mendoza, CP: 5500. Email: luisnicolasperrone@gmail.com 


\section{Introducción}

La identidad puede entenderse de muy distintos modos, con base en las diversas determinaciones que ha experimentado a lo largo de su historia filosófica, ya sea como un concepto meramente lógico o como supeditado a la subjetividad, y en esta medida, comprendido como un concepto narrativo, formal, emancipatorio, democrático, entre otros. Ahora bien, sea cual sea la posición filosófica a partir de la cual se aborde la identidad, hay ciertas nociones que son ineludibles y que operan activamente en su delimitación. Estas nociones son alteridad y reconocimiento, las cuales podríamos reducir simplemente a la cuestión "del otro", es decir, a la pregunta por el rol que desempeña el otro en la determinación de la identidad.

De esta manera, intentaremos abordar la mencionada problemática a través de la postura filosófica de Karl-Otto Apel, esto es, dilucidar de qué manera está operando la cuestión de la identidad en la configuración del pensamiento del autor. Para llevar a cabo esta tarea, sustentaremos nuestro punto de partida en una distinción teórica de la identidad en tanto mismidad, por un lado, y en cuanto ipseidad, por el otro; distinción aportada por Paul Ricoeur (2006). Cabe aclarar que no nos detendremos en un análisis pormenorizado de la ontología del si que el filósofo realiza a propósito de estos conceptos, y que el presente estudio no es una aplicación ulterior de los mismos. Por el contrario, solo nos interesa la mencionada distinción en la medida que constituye una contribución muy clarificante respecto al tema abordado, es decir, nos valdremos de ella solo metodológicamente. Aclarado esto, especifiquemos ahora la mencionada distinción conceptual. Las estructuras de la mismidad y de la ipseidad adquieren su significatividad por la referencia de la identidad al idem o al ipse, respectivamente. En este sentido, la mismidad como identidad-idem se configura a partir de la oposición de lo diferente de sí, lo cual quiere decir que lo otro es entendido como algo contingente, variable, en contraposición de un cierto núcleo no alterable de la mismidad. La ipseidad como identidad-ipse, por el contrario, no excluye como constitución propia la presencia de lo otro o lo diferente, sino que "la ipseidad del sí mismo implica la alteridad en un grado tan íntimo que no se puede pensar en una sin la otra" (Ricoeur, 2006, p. 14). Esto es así debido a una equiparación entre alteridad e ipseidad, es decir, que una superación de la oposición sí mismo-otro es solamente posible si entendemos una relación dialéctica entre dichos términos, la cual sea coimplicativa. Así, pues, al desplegar la comprensión de la identidad como un sí mismo en tanto otro, determinamos la estructura de la ipseidad.

Según esto, intentaremos realizar una aproximación a la cuestión del funcionamiento de la identidad en el pensamiento filosófico de Karl-Otto Apel. Para ello, mostraremos que la inclusión del otro juega un papel decisivo, ya que, en primer lugar, su postura se manifiesta como la necesidad de una superación de la tradicional filosofía de la conciencia a través de una transformación de la misma. Esta consiste, en breves términos, en un paso del yo-pienso al 
nosotros-argumentamos. De esta forma, Apel pone en evidencia la estructura dialógica inherente a la racionalidad, lo cual implica varios aspectos.

En primer lugar, es menester reparar en el hecho de que el pensador aún mantiene una noción fuerte de racionalidad, lo cual lo sitúa en el polo contrario respecto de las filosofías contemporáneas de corte deconstruccionista y de la crítica que condena la racionalidad como mecanismo coercitivo. Ya el fracaso del proyecto ilustrado de una razón astuta tendiente a un progreso histórico hacia lo mejor culminó, más bien, en postulados netamente ideológicos que, tras la fachada de la libertad y la igualdad, configuraron relaciones de dominio cada vez más fuertes. El pensamiento contemporáneo reacciona beligerantemente contra esta concepción de la racionalidad, y renuncia en toda medida a la exigencia de una fundamentación última de los relatos. Esta postura es válida en cuanto brinda la pauta de una afirmación historicista de las multiplicidades y acentúa la contingencia de las determinaciones de la facticidad en la que se halla situado el sujeto. Sin embargo, Apel se manifiesta abiertamente en contra de esta actitud, ya que considera que la fáctica situación del hombre en la era de la ciencia acarrea indefectiblemente la necesidad de fundamentación de normas. Por ello, su desafío es pensar una dimensión comunicativa de la racionalidad, que permita problematizar las pretensiones de validez universal en el discurso intersubjetivo. Para llevar a cabo este cometido, Apel demuestra que la racionalidad posee una estructura dialógica, mediante una transformación pragmático trascendental de la filosofía moderna de la conciencia. En este sentido, vemos que dicha transformación está operada por un triple influjo: la hermenéutica (Heidegger), la lingüística (segundo Wittgenstein) y la semiótica (Peirce).

En las páginas subsiguientes, pondremos en evidencia de qué manera realiza Apel esta transformación de la filosofía y cómo se constituye la racionalidad dialógica, para de ese modo configurar una identidad-ipse. Veremos que la ipseidad se construye por medio de estructuras formales, pero que no dejan de lado la referencia a la situacionalidad de la historia de una determinada comunidad, permitiendo, así, el juego de la libertad y de la responsabilidad en relación con el otro.

\section{Identidad y transformación de la filosofía. La modernidad y la mismidad}

El proyecto apeliano de una transformación de la filosofía tiene como objetivo la menesterosidad de superar la moderna filosofía de la conciencia, más concretamente la postura kantiana de la apercepción trascendental, en virtud de una filosofía de las condiciones intersubjetivas de validez en el discurso argumentativo. En este sentido, es lícito hacer una lectura de aquella concepción moderna como la de una identidad-idem, esto es, como mismidad. Esta se manifiesta en la configuración de un sujeto intelectual ejemplar, que va desde el cogito de Descartes y se extiende, inclusive, hasta el ego trascendental fenomenológico 
de Husserl. Según lo planteado, Hugo Ibarra Ortiz (2009) considera que la modernidad cayó en el "olvido del hombre" al alejarlo de la experiencia de la cotidianeidad e intersubjetividad y colocarlo bajo el cristal de la universalidad:

En el intento desesperado de salvarse por su propia mano [...], de darse a sí mismo todas las condiciones de posibilidad de su existencia, de bastarse a sí mismo, de crearse por sí solo y sobre todo, en su afán de dominio del ser o de la naturaleza, o de los demás seres humanos, de conocer más y mejor, de hacerse dios; ha dejado de lado el bienestar de los hombres, la responsabilidad, el amor, la solidaridad, la caridad, los sentimientos, inclusive la libertad. (párr. 2)

Es por estas vías por donde verdaderamente corre el planteamiento de una transformación de la filosofía de la conciencia, entendida esta como autónoma y solipsista. La evidencia del cogito ergo sum cartesiano, la unidad sintética de la apercepción trascendental kantiana, la idea absoluta hegeliana y el ego trascendental fenomenológico husserliano son casos paradigmáticos de tal posición filosófica representativa de la mismidad. Si bien no entraremos en los pormenores de cada filosofía, aclararemos esto brevemente.

El cogitans sum es la evidencia que Descartes establece como indubitable. En efecto, la duda hiperbólica lo lleva a desconfiar de todo, principalmente de los sentidos, de los cuales es imposible fiarse, ya que, si alguna vez han engañado, pueden hacerlo siempre. Por lo tanto, si todo lo tenido por verdadero es falso, si todo es un engaño obra de un genio maligno que se burla de mí, entonces hay una certeza que Descartes descubre: la certeza del acto de dudar. Y si el sujeto duda, esto quiere decir que necesariamente debe existir para poder hacerlo. De esta manera, llega a la evidencia del cogito ergo sum, es decir, la posibilidad conocer la existencia por medio del pensamiento. El pensamiento es la primera actividad que no es posible negar sin contradecirse, pues para negarlo hay que usar el mismo pensar. Así, existe una identidad entre pensar y ser. Y la existencia del pensamiento, del alma, es más fácil de conocer que la del cuerpo, pues es una evidencia clara y distinta. El cuerpo o lo extenso, en realidad, es cognoscible por derivación; el pensar es la condición de posibilidad para conocerlo. Afirma Descartes (2004): “conocí por ello que yo era una substancia cuya total esencia o naturaleza es pensar, y que no necesita, para ser, de lugar alguno ni depende de ninguna cosa material"' (p. 52). El cogito, pues, no es un sujeto situado; es solipsista porque no requiere de la referencia al otro para configurarse; su identidad es mismidad, pues es totalmente autónomo y diferente de lo otro.

Kant, en cambio, rescata la empiria de la degradación a la que la condujo el racionalismo. Reconoce que todo conocimiento comienza "con" la experiencia, pero aclara que no todo él se origina "en" ella. Precisamente, el material múltiple que es recibido por los sentidos debe ser subsumido en una unidad. La primera síntesis es la operada por las intuiciones a priori de la sensibilidad: espacio y tiempo. Dichas intuiciones deber ser subsumidas bajo conceptos $a$ priori del entendimiento: las categorías. Por lo tanto, para conocer es necesario 
referir los conceptos puros a objetos de una experiencia posible. Sin embargo, hay un abismo entre los fenómenos y los conceptos, por lo cual debe haber un tercer elemento que medie entre ellos: los esquemas trascendentales, que son determinaciones del tiempo, pues este está en homogeneidad, por un lado, con el fenómeno, ya que el tiempo subyace a toda representación de lo múltiple; y por otro, con la categoría, ya que es universal. Así, el conocimiento requiere la referencia de las categorías a objetos. Este es el problema de la deducción trascendental. Kant necesita establecer un principio supremo del uso del entendimiento, y pone como tal la apercepción. La apercepción trascendental es la unidad de la conciencia que acompaña a todas las representaciones y que permite que las mismas sean representaciones para un sujeto. "La unidad trascendental de la apercepción es la que une en un concepto del objeto todo lo múltiple dado en una intuición. Por eso llámase objetiva" (Kant, 1979, p. 83). De esta manera, para Kant, solamente desde la unidad de una conciencia es posible conocer los fenómenos. Evidentemente, esta autoconsciencia es solipsista, pues si bien el yo-pienso no es un noumeno, sino que posee experiencia y representaciones, él solo, como unidad sintética, es la garantía de objetividad del conocimiento. Lo otro, el otro, le es ajeno e innecesario para tal conocimiento. Esta autoconciencia es mismidad.

En la filosofía de Hegel, el problema se ubica en otro nivel, pues él hace entrar en juego la noción de reconocimiento como elemento esencial del movimiento dialéctico. Esto es claro en la dialéctica del amo y el esclavo, donde Hegel muestra que la aparición del otro es necesaria para que la conciencia se vuelva conciencia de sí. Específicamente, dice (2007): “La autoconciencia es en y para sí en cuanto que y porque es en sí y para sí para otra autoconciencia; es decir, solo en cuanto se la reconoce" (p. 113). En principio, cada una de las autoconciencias es solo para sí, excluye todo otro porque está cierta de sí; por lo tanto, se da una relación de lucha entre ambas, donde se debe eliminar a la otra que le es extraña para alcanzar la verdad de sí misma. Ahora bien, la relación de las conciencias no es simétrica, pues una de ellas se aleja del mundo de las cosas, es independiente, es el señor que quiere estar solo consigo mismo; la otra, en cambio, tiene una relación directa con la cosa, a la cual transforma ya que necesita conservarla pues siente el temor de estar totalmente sola, cual señor absoluto. Sin embargo, la autoconciencia se da cuenta de que si elimina a la otra nadie puede dar cuenta del logro de su libertad; así, la lucha ya no es entonces a muerte, sino por el reconocimiento. Asimismo, y por causa de esto, el amo se percata de que es dependiente del esclavo, pues necesita que otra autoconciencia lo reconozca como independiente. De esta manera, el señor se vuelve siervo; este se vuelve lo más necesario, es la verdad del amo. Por lo tanto, la conciencia de sí aparece por mediación del otro, en tanto depende del otro. El solipsismo desaparece. No obstante, aquí sigue Hegel hablando en términos de conocimiento. No se reconoce al otro por su individualidad y facticidad, sino en cuanto puede transformar mi certeza de sí en verdad. En definitiva, nos parece que el reconocimiento tiende a la afirmación de la mismidad de la conciencia, más allá de que sea la dependencia del otro la que la posibilite. Las pluralidades no encajan. Esto es evidente en la determinación de la eticidad, donde el espíritu 
se eleva a su estadio superior cuando las individualidades quedan disueltas en el elemento universal del Estado (que para Hegel es más concreto porque posee mayor contenido). La persona, en última instancia, es contingente e inesencial, un momento cuya verdad se alcanza en el todo. En este punto es pertinente recordar a Sartre, quien, apoyando a Kierkegaard, reivindica al individuo: "El individuo reclama su cumplimiento como individuo, el reconocimiento de su ser concreto, y no la explicación objetiva de una estructura universal" (Sartre, 2006, p. 337).

Husserl, por su parte, está preocupado también por evitar el solipsismo. Sin embargo, su filosofía es abiertamente una filosofía de la conciencia. En su afán de alcanzar una evidencia apodíctica, Husserl realza el yo hasta una posición absoluta. En efecto, por medio de las reducciones fenomenológicas, ve que el último reducto puro que queda es el de la conciencia, que se distingue de la esfera de lo empírico. El ego trascendental, puro, con sus cogitationes, sus vivencias y contenidos, es la primera evidencia. Pero esta conciencia no es un ámbito vacío, sino que es siempre intencional, pues se refiere a un objeto, a un mundo, y al hacerlo le otorga sentido. De esta manera, el mundo es resultado de las cogitationes del ego, de su intencionalidad, y en este sentido, el ego no puede salir de sí. En rigor, Husserl pretende evitar el solipsismo apelando a una cierta intersubjetividad como recurso indispensable para la constitución del mundo. Dice que con la aparición de lo otro, "se superpone otro sentido, de un modo general, sobre mi mundo primordial, en virtud de lo cual este se convierte en aparición de un determinado mundo objetivo" (Husserl, 1997, p. 142). El otro, en realidad, es una garantía de la objetividad. Las cosas, los objetos no están simplemente referidos a un sujeto, sino a un conjunto de conciencias. "El prójimo sería allí como una categoría suplementaria que permitiría constituir un mundo, no como un ser real existente allende ese mundo" (Sartre, 2006, p. 330). Pero el problema se agrava cuando reconocemos que el ego, en tanto conciencia intencional, también se refiere al alter ego como a un objeto que aparece en su experiencia. Así, el ego es el que le da sentido al otro; el alter ego se vuelve un fenómeno inmanente del ego. Estas proposiciones, en consecuencia, hacen lícito el considerar a Husserl como un moderno, pues no puede escapar de la mismidad de la conciencia.

\section{Transformación hacia la ipseidad. El giro hermenéutico-lingüístico-semiótico}

Teniendo en cuenta la concepción moderna de sujeto, y para superarla, Apel considera que es necesario llevar a cabo una transformación de la filosofía en la cual se tenga como miramiento principal la relación sujeto-cosujeto, esto es, el carácter dialógico e interrelacional de la subjetividad. Esto implica transformar "la filosofía clásica de la conciencia, que parte del individualismo metódico, en una filosofía transcendental del lenguaje que reconoce el carácter dialógico, comunicativo de la razón" (Apel, 1985, p. 68). En efecto, Apel se da cuenta de 
que el carácter dialógico de la racionalidad está determinado por la estructura irrebasable del lenguaje. Este es un a priori ineludible que está mediando toda relación comunicativa. Es por ello, que su postura filosófica plantea un giro hermenéutico-lingüístico-semiótico, influenciado respectivamente por Martin Heidegger, Ludwig Wittgenstein y Charles Peirce, giro que identificará con el título de pragmática trascendental. Esta reflexión sobre una comunidad intersubjetiva de habla, donde aparece un nosotros argumentamos, en lugar de un yo pienso, es la modalidad que encuentra Apel para superar el solipsismo moderno.

La modernidad, en la determinación de su filosofar, apela a un recurso metódico que resulte indubitable, irrebasable, un punto supremo y último. En el caso de la reflexión kantiana, este recurso irrebasable es el de la unidad de la apercepción, que debe acompañar a todas las representaciones del yo. Esto es característico del pensar solipsista de la mismidad basado en la relación sujeto-objeto. Este planteamiento es el que Apel pretende superar, mostrando el carácter dialógico de la subjetividad o, lo que podríamos decir de otra manera, mostrando la configuración de una identidad que sostiene la relación sujeto-cosujeto. Esta implicación del otro, esta ipseidad, es solamente posible si se opera una transformación del mencionado posicionamiento moderno, que tenga en cuenta la dialogicidad de la razón, para lo cual es necesario abandonar el punto supremo del yo pienso y sustituirlo por otro. De esta manera, para que la razón se construya en referencia a la inclusión del otro debe ser, según Apel, de carácter comunicativo. Por ello, el punto irrebasable de una nueva filosofía transformada será el lenguaje. Este es el verdadero a priori que se encuentra mediando todas las relaciones comunicativas, que son, en este sentido, argumentativas. El lenguaje, así, es "el rival más importante del a priori de conciencia, [y pertenece] a la pre-estructura hermenéutica del mundo de la vida. [...] ese a priori posibilita la validez intersubjetiva del pensamiento reflexivo en el marco del discurso argumentativo" (Apel, 2009, p. 117; cursiva añadida).

Asimismo, es preciso aclarar que cuando Apel se refiere al lenguaje como "hecho último", no está queriendo darle un carácter absoluto metafísico, sino que pretende mentar su índole de condición de posibilidad de todo discurso argumentativo. El lenguaje es el presupuesto más allá del cual no se puede ir, ya que, si se pretendiera negarlo o cuestionarlo, se debería recurrir a la argumentación como modo de expresión, lo cual es una evidente contradicción. Es por ello que el giro apeliano es pragmático trascendental, y dentro del mismo se encuentran articulados concepciones hermenéuticas, analítico-lingüísticas y semióticas.

Para llevar a cabo semejante transformación de la filosofía, Apel incorpora, en primer lugar, el aporte de la hermenéutica. Para Heidegger, esta se encarga de poner de manifiesto la interpretación que la facticidad hace de sí misma, esto es, la interpretación del existir en cada ocasión. No se trata de que la hermenéutica tenga la existencia concreta (facticidad) por objeto, sino que aquella es un modo de ser de la facticidad. Por lo tanto, la comprensión que despliega la hermenéutica tiene una estructura previa ya-interpretada, un cierto haber previo dentro del cual se mueve la interpretación. "La hermenéutica no tiene por 
objetivo la posesión de conocimientos, sino un conocer existencial [...]; habla desde lo ya-interpretado para lo ya-interpretado" (Heidegger, 1999, p. 37). Tal pre-comprensión del ser-en-el-mundo es lo que le interesa recuperar a Apel, pues considera que supera la dicotomía sujeto-objeto; sin embargo, critica a Heidegger el hecho de identificar el sentido con la verdad entendida como desocultamiento (aletheia), pues al poner su confianza en el destino del ser, de algún modo estaría atándose a la metafísica que hay que abandonar. La transformación filosófica apeliana requiere, pues, de una estructura anticipativa del comprender. Dicha estructura funciona en lo que Apel llama la "comunidad comunicativa ideal", la cual es el espacio regulativo de fundamentación del discurso como "unidad intersubjetiva de interpretación, en tanto que comprensión del sentido y consenso de la verdad" (Apel, 1985, p. 391). Este punto de vista hermenéutico es fundamental en el planteo del autor, ya que implica que la constitución de sentido está mediada por el lenguaje, pero al mismo tiempo, dicha constitución es posible por las relaciones sujeto-cosujeto. Esto es imprescindible para la afirmación de la ipseidad, ya que es imposible pensar en la comprensibilidad si no se tiene en cuenta la relación con el otro. La comprensión del sentido es, por ello, cooperativa y tiene como norte el acuerdo y el entendimiento con los otros, en virtud de la construcción de un sujeto colectivo, de un nosotros.

En segundo lugar, la ya mencionada transformación precisa también de una estructura lingüística "viva" o "juego del lenguaje". Esto es precisamente lo que estudia el segundo Wittgenstein. Este analiza los fenómenos lingüísticos atendiendo al uso o empleo de las palabras a fin de poner de relieve el significado en el funcionamiento de las mismas. El designar es tan solo uno de los modos de empleo del lenguaje, pero hay innumerables tipos de uso que varían continuamente, tales como obedecer o dar órdenes, formular hipótesis, especular, saludar, actuar en teatro, etc. (Wittgenstein, 1988, p. 39). Todos estos son múltiples juegos, y no existe uno privilegiado. Wittgenstein critica a los lógicos (y a sí mismo en su primera etapa, la del Tractatus) porque describen el lenguaje solamente en sí mismo, lo cual es erróneo, pues no se puede separar de su contexto de uso. Por ello, utiliza la expresión juego de lenguaje, la cual indica que hablar el lenguaje forma parte de una actividad o de una forma de vida. Lo que Apel rescata es el uso de una determinada configuración lingüística (juego) en una determinada comunidad socio-históricamente condicionada. Sin embargo, no cree que el enjuiciamiento de tales formas de vida fácticas sea el que determine la normatividad del discurso, sino que, en realidad, esta tarea la logra la presuposición de un juego trascendental del lenguaje, esto es, una suerte de acuerdo intersubjetivo previo sobre los signos como condición de posibilidad de la comunicación efectiva. Por lo tanto, Apel afirma:

Wittgenstein, al radicalizar el convencionalismo pragmático [...] no ha refutado realmente la idea de una regla trascendental del acuerdo [...]. Porque, en efecto, también los juegos lingüísticos fácticamente existentes presuponen ya virtualmente la unión intrínseca entre el uso de los signos, la praxis del comportamiento y la comprensión del mundo. (1985, p. 154) 
En tercer lugar, la teoría de Peirce hace un aporte invaluable al planteamiento de Apel. En efecto, Peirce muestra que todo conocimiento está mediado por signos y, lo que es aún más importante, va más allá de la correspondencia entre sentido y referencia, pues repara en el uso que es posible hacer de los mismos. Esta postura es fundante del pragmatismo. Asimismo, es importante detenerse brevemente en otro aporte del autor: la distinción de la tridimensionalidad de la función sígnica. Como explica Apel (1985, p. 162), Peirce había definido al signo como un ente que representa otra cosa para alguien (intérprete) y distingue tres categorías: primeridad, segundidad, terceridad. La primeridad refiere la función icónica del signo, esto es, una cualidad carente de relaciones, ser signo de sí mismo, expresarse como algo. La segundidad mienta el uso indicativo, es decir, como signo de un objeto al cual denota. La terceridad muestra el uso simbólico, lo que quiere decir que el signo es interpretado por un sujeto interpretante. Ahora bien, esta última categoría es la que resulta interesante para Apel, pues el interpretante de Peirce no es un sujeto solipsista al modo moderno, sino una comunidad que utiliza tales signos y genera el acuerdo sobre su sentido. Los individuos finitos no pueden alcanzar de manera aislada la verdad (entendida como el acuerdo en la lógica de la ciencia), por lo cual Pierce postula la necesidad de una comunidad ilimitada de investigadores, en la cual cada científico asume una actitud de autorrenuncia (a sus intereses) en virtud de contribuir a un proceso ilimitado de mediación dentro de dicha comunidad, es decir, de incremento del conocimiento, a través de lo cual se puede alcanzar la meta de la verdad. Por tanto, Apel rescata la importancia del usuario del lenguaje (de los signos) y esto le sirve como base para la postulación de su comunidad ideal de argumentación.

En suma, el giro realizado por Apel lo conduce hacia un concepto hermenéuticotrascendental del lenguaje. Él considera que este último es, ciertamente, la condición de posibilidad de la intersubjetividad porque demuestra el carácter dialógico de la racionalidad, lo cual implica que el sujeto se encuentra siempre ya en una relación con otro y que la identidad se construye a partir de dicha relación. Ahora bien, los sujetos se hallan inmersos en determinados contextos donde el lenguaje tiene un uso particular, donde se constituye a partir de los distintos modos de vida. Esto define diversos juegos de lenguaje en los que los individuos participan y a partir de los cuales determinan el sentido.

Los lenguajes no son evidentemente independientes de la "interpretación" tal como propuso la concepción logicista del sistema lingüístico: la posibilidad de acuñar previamente la comprensión subjetiva del sentido implica más bien la posibilidad inversa de reestructurar el componente semántico del lenguaje "vivo", mediante el acuerdo sobre el sentido logrado pragmáticamente en el nivel del uso del lenguaje (Apel, 1985, p. 335).

No obstante, Apel agrega que estos juegos lingüísticos deben poder ser remitidos a una estructura anticipativa ulterior, es decir, a una suerte de juego de lenguaje ideal (trascendental) del que participan todos los seres racionales, y en el cual es posible el acuerdo sobre el sentido de los signos. 


\section{Identidad y racionalidad. El olvido del logos}

Apel, a diferencia de la mayoría de las posturas filosóficas contemporáneas, no renuncia a la idea de una razón fuerte, y se manifiesta abiertamente contra las críticas referidas a esta, en cuanto pretenden desterrarla totalmente.

Una de las críticas más interesantes y acérrimas contra la racionalidad es la efectuada por Nietzsche. En rigor, lo que el filósofo hace es una depotenciación de la noción de razón, y la coloca en un nuevo sitio, antes impensado para aquella. El filósofo considera que la razón es uno más de los instintos, no más privilegiado que cualquier otro que sirva para la afirmación de la vida. Dice al respecto:

[...] tampoco es la consciencia, en ningún sentido decisivo, antitética de lo instintivo, la mayor parte del pensar consciente de un filósofo está guiada de modo secreto por sus instintos y es forzada por estos a discurrir por determinados carriles. También detrás de toda lógica y de su aparente soberanía de movimientos se encuentran valoraciones o, hablando con mayor claridad, exigencias fisiológicas orientadas a conservar una determinada especie de vida. (2007, pp. 23-24)

Aquí se evidencia el nuevo espacio que Nietzsche le otorga a la razón, el cual no es del todo desestimable. Justamente, en tanto aquella favorezca la vida, es útil. Y lo que favorece la vida es instintivo, es decir, es una fuerza, un ímpetu afirmativo. El hombre no puede reducirse a meras operaciones racionales; desconocer este aspecto es, diría Nietzsche, una bobería. No le interesa el valor de verdad o falsedad de un juicio; este es un engaño. Pero agrega que "el hombre no podría vivir si no admitiese las ficciones lógicas, si no midiese la realidad con la medida del mundo puramente inventado de lo incondicionado, idéntico-así-mismo" (Nietzsche, 2007, p. 24). Así, pues, estas no-verdades, estas ficciones útiles, son condiciones de la vida, y una polémica resignificación que hay que admitir: "una filosofía que osa hacer esto se coloca, ya solo con ello, más allá del bien y del mal" (Nietzsche, 2007, p. 24). En este sentido, el asalto nietzscheano pretende superar la comprensión de la razón como un modo del entendimiento o de la conciencia pensante diluyéndola en el elemento fisiológico. En palabras de Jaspers:

[...] solo cuando no se la confunde con el mero entendimiento o con el intelecto que fija al conocer, es decir, con la finitud teleológica, sino cuando la razón se hace consciente [...] del todo orgánico de sus funciones, solo entonces el filosofar puede permanecer fiel a sí mismo en el gran movimiento de su historia. (2003, p. 235)

No obstante, estas interpretaciones, Nietzsche deja bien claro que todo pensar por categorías, todo pensar entendido como mera facultad teórica, es una ficción. Una ficción que, en todo caso, permite referirse al ser, pero que no lo constituye. Por lo tanto, el filósofo rechaza la razón objetiva y la absolutización de la misma, 
ya que eso "equivaldría, para él, a tornar invisible al ser mismo" (Jaspers, 2003, p. 24). Nietzsche sospecha de la confianza en el yo como conciencia idéntica a sí misma, sustentada por la no contradicción, cerrada sobre sí misma. La fisonomía del mundo es, en realidad, dispersa, caótica, en constante devenir, configurada en caracteres inconmensurables, lo cual la hace inasible y no subsumible bajo una regla. La razón, en consecuencia, no puede ser un principio inteligible y originario que prevalece en el mundo; esa concepción ha sido una de las máscaras de Occidente que es preciso hacer caer. La confianza en esta racionalidad es meramente una fe metafísica, la cual es insostenible, pues está proyectada desde un topos ajeno a la vida, que la niega, que demuestra el vaciamiento de sentido, el nihilismo de Occidente; o dicho en otros términos, que después de la muerte de Dios, ha muerto también.

Derrida, por su parte, despliega una crítica contra el logocentrismo dentro de lo que él llama, más precisamente, el fonocentrismo. En efecto, entiende que toda la tradición ha favorecido un privilegio de la phoné por sobre la escritura, ya que ha concebido la voz como la productora de los primeros símbolos y, por lo tanto, como la que tiene una relación directa con el pensamiento. "Así la época del logos rebaja la escritura, pensada como mediación de mediación y caída en la exterioridad del sentido" (Derrida, 1971, p. 19). Por este motivo, la tarea de Derrida es la de una recuperación de la escritura, la de una gramatología, pues el lenguaje es, según él, puramente escritura. No se puede poner ningún signo lingüístico antes de la escritura (ya aclararemos lo que él refiere con este concepto). Derrida reconoce a Nietzsche el logro de haber liberado el significante de la subsunción al logos absoluto, y entiende que la escritura no descubre su sentido en una verdad original, apriorística, incondicionada. Es necesario deconstruir esta época que postula el primado del logos, el cual es metafísico-teológico para Derrida, pues tiene su base en la distinción entre significante y significado, que supone la distinción entre lo sensible y lo inteligible.

El sistema del oírse-hablar a través de la sustancia fónica-que se ofrece como significante no-exterior, no-mundano, por lo tanto, no-empírico o no-contingente- ha debido dominar durante toda una época la historia del mundo, ha producido incluso la idea de mundo, la idea de origen del mundo a partir de la diferencia entre lo mundano y lo no-mundano, el afuera y el adentro, la idealidad y la no-idealidad, lo universal y lo nouniversal, lo trascendental y lo empírico, etcétera. (Derrida, 1971, p. 13)

De este modo, la escritura queda reducida a una función subalterna, mera transcriptora de un habla originaria. Derrida, por el contrario, le da un nuevo lugar. Antes que nada, la escritura desborda el simple concepto de lenguaje y, a su vez, lo incluye. Modos de lenguaje como gestos, son también escritura. De esta manera, Derrida evita que su planteo se convierta en una sustitución de un absoluto, el fonocentrismo, por otro, la escritura. Esta es, en rigor, todo sistema significante y la totalidad de aquello que lo posibilita; no se reduce a lo escrito ni al acto de escribir. La escritura es toda simbolización que, a su vez, no puede abarcar la totalidad del significado. "La racionalidad [...] que dirige 
la escritura así ampliada y radicalizada, ya no surge de un logos, [sino que] inaugura la destrucción, no la demolición sino la des-sedimentación, la desconstrucción de todas las significaciones que tienen su fuente en este logos" (Derrida, 1971, p. 16-17). Por lo tanto, la crítica derridiana a la razón (entendida como fonocentrismo), desemboca en la necesidad del deconstruccionismo. La deconstrucción, pues, no es un método en sentido estricto, sino, más bien, un programa para desmantelar el logocentrismo. A través de esta estrategia se pretende buscar el significado de un texto más allá del texto mismo, entendiendo que este no puede mostrarlo en modo total y que, por ello, el significado no es meramente el expuesto. Consecuentemente, el análisis deconstructivo debe indagar por los márgenes del texto, atendiendo a los lugares desapercibidos, como notas y comentarios al pie, textos poco difundidos, entre otros. Así, el espacio de manifestación del sentido no se reduce a la centralidad del texto, sino que se amplía hacia la marginalidad del mismo. En este nuevo espacio se devela cierta indecibilidad del sentido; aparece la différance. La différance señala la imposibilidad de un sentido unívoco y que este, en realidad, se constituye por la relación de los signos entre sí y de sus diferencias. Por consiguiente, un determinado elemento de un texto no vale por sí mismo, no se sustenta por su presencia (aquí se evidencia la crítica que Derrida hace a las filosofías de la presencia como fuentes del logocentrismo). Así, dice Derrida (1989):

La diferencia es lo que hace que el movimiento de la significación no sea posible más que si cada elemento llamado presente, que aparece en la escena de la presencia, se relaciona con otra cosa, guardando en sí la marca del elemento pasado y dejándose ya hundir por la marca de su relación con el elemento futuro. (p. 48)

De este modo, la différance es la estructuración, el entramado de diferencias que ella produce y, al mismo tiempo, la temporización de aquellas, el aplazamiento del sentido. Muestra el proceso de producción del sentido, donde este no es absoluto, sino que siempre está referido a otro elemento. Es una suerte de origen anti-originario, "el origen no-pleno, no-simple, el origen estructurado y diferente (de diferir) de las diferencias" (Derrida, 1989, p. 47). El sentido es el producto de las diferencias y está emplazado en el tiempo.

En el caso de la postura de Lyotard se pueden apreciar, de modo representativo, las críticas del pensamiento posmoderno con respecto a la razón. Efectivamente, él cree que el proceso de industrialización ha llevado a la cultura y la ciencia a una transformación en las reglas de sus juegos que hace imposible el sostenimiento de sistemas de pensamiento que pretendan autolegitimarse y erigirse como meta-relatos omnicomprensivos de la realidad. De esta manera, todo discurso que pretenda legitimarse apelando a un gran relato, es decir, a una construcción teórica sistemática y absoluta, es un discurso científico perteneciente a la modernidad. El discurso posmoderno, en cambio, es aquel que, reconociendo la caída de los grandes relatos, "hace más útil nuestra sensibilidad ante las diferencias, y fortalece nuestra capacidad de soportar lo inconmensurable" (Lyotard, 1987, p. 11). Esto quiere decir que se legitima en la pluralidad, que "no encuentra su 
razón en la homología de los expertos, sino en la paralogía de los inventores" (Lyotard, 1987, p. 11). Por lo tanto, la razón es entendida como un elemento homogeneizante y coercitivo, y es fruto de la modernidad, ya que la concepción de la racionalidad autónoma y fundamentadora de la totalidad terminó consolidando ciertos sistemas ideológicos de dominio. En el saber actual, tal fuerza de dominio se traduce en el poder que brinda la manipulación de la información, y convierte al conocimiento en una mercancía, "el saber se ha convertido en los últimos decenios en la principal fuerza de producción" (Lyotard, 1987, p. 16). El rol del filósofo, por lo tanto, está absolutamente desligado de los sistemas absolutos; al respecto, dice Lyotard:

Se pierde como maestro de conceptos y de edificios de conceptos; tiene que meterse, de esta manera, en la escuela de ciencias y técnicas. Ya se pasó el tiempo para él de pensar en erigir una metrópoli para el pensamiento, tal como la comunidad moderna le había encargado y le había concedido el crédito haciendo de él el profesor de la universalidad. (1996, pp. 28-29)

En contraposición a estas posturas, Apel mantiene un concepto sólido de razón, aunque absolutamente depurado de cualquier connotación metafísica. El filósofo deja bien claro que no intenta postular una absolutización de la razón, por considerar esto un modo aislado y abstracto de la misma (podríamos decir, característico de la mismidad), y por lo tanto deficiente. En este sentido, comparte la crítica operada por las filosofías detractoras de la racionalidad. No obstante, esto no lo conduce a una negación de la razón. Por el contrario, el concepto de racionalidad que el autor maneja se refiere tan solo a una competencia que brinde la posibilidad de argumentar y establecer consenso sobre la validez del discurso, en el cual todos los miembros de una comunidad son partícipes. Las proposiciones de un diálogo intersubjetivo deben ser comprensibles para los interlocutores, por lo cual, la apelación a la verdad o pretensión de validez es ineludible. En este sentido, Apel no renuncia a la racionalidad, sino que la requiere $y$, por otra parte, cuestiona las críticas efectuadas contra aquella, ya que estas pretenden que su discurso crítico sea también válido, lo cual es una contradicción dentro de las condiciones del discurso lingüístico. Por ello, afirma que han olvidado el logos. El intento de superar el logocentrismo es lícito, incluso para Apel, pero no se puede eludir que la argumentación necesita el recurso racional para expresar enunciados válidos sobre el mundo de la vida.

\section{Reconstrucción de los tipos de racionalidad}

La pregunta directriz de Apel es: “ ¿Existe una racionalidad especial de la interacción social que no puede ser reducida a la racionalidad medio-fin del actuar de los sujetos particulares?" (1999, p. 29). En efecto, él tiene constantemente en vista una doble necesidad: la de una fundamentación normativa y la de una intersubjetividad. Por lo tanto, la racionalidad que dé cabida a la ipseidad tiene 
que ser una de carácter ético, que incluya ineludiblemente la realidad de las interacciones humanas. Al mismo tiempo, debe poder ser diferente de la razón meramente instrumental que regula los intereses particulares y teleológicos de los individuos. Es por estos motivos que distingue dos grandes tipos de racionalidad: una estratégica-teleológica y otra ética-comunicativa. Es esta última la que revela verdaderamente el carácter dialógico de la razón y la que permite la construcción de una identidad-ipse, esto es, una identidad que no excluya la alteridad del otro.

En primera instancia, Apel se vale del planteo que Max Weber hace sobre la cuestión de la racionalidad de la acción social. Efectivamente, Weber distingue dos grados básicos de la racionalización: uno teleológico o estratégico, que corresponde al actor que escoge sus objetivos y medios para alcanzarlos sin dejar de lado las consecuencias que éstos acarrean; este es el estadio más alto. Otro grado es el de una racionalidad valorativa, que se concreta cuando un determinado actor considera como incondicionadamente válida cierta forma de acción, y no pondera las consecuencias de la elección de los medios para realizarla. Esta última abraza, evidentemente, la concepción kantiana del deber, y constituye lo que Weber llama una "ética de la convicción", la cual está menos racionalizada que la primera (la teleológica), ya que no incluye el cálculo de los efectos, y por eso no es una ética de la responsabilidad. En este sentido, un proceso de racionalización supone un arraigo cada vez mayor de la razón estratégica y contribuye a un desencantamiento del mundo, es decir, a la desaparición de los presupuestos cosmovisionales. Según esto, Weber pretende ampliar la noción de racionalidad en la interacción social al introducir, además, la reciprocidad de las acciones. En efecto, para el sociólogo, los actores aplican tal razón estratégica sabiendo que están inmersos en un juego donde los demás también operan del mismo modo. Por ello, los sujetos calculan sus propios beneficios y los de los demás, pues el éxito depende de las acciones recíprocas. En consecuencia, los otros actores funcionan tan solo como medios en la persecución de fines que, en definitiva, son particulares. Esto no contribuye en la construcción de la ipseidad. Así, Apel critica que la interacción estratégica no permite comprender la función mediadora del lenguaje que está efectivamente operando en toda interacción. Es por eso que debe incorporarle la teoría de la acción comunicativa de Habermas (a la cual él mismo ha contribuido).

Jürgen Habermas propone una teoría sobre los modos de interacción mediados por la comunicación. Esta pretende poner de manifiesto la coordinación de acciones teleológicas y extralingüísticas, no en el sentido de Max Weber, sino en el de una comprensión a través de actos lingüísticos. Esto significa que el actuar está orientado hacia la comprensión y no hacia el éxito, y tal comprensión es efectiva solo en el ámbito del discurso. A Habermas, como a Apel, también le parece insuficiente el modelo teleológico y estratégico de la racionalidad para explicar la función del lenguaje en la interacción. Consecuentemente, Habermas (1987), dice: 
Solo el concepto de acción comunicativa presupone el lenguaje como un medio de entendimiento sin más abreviaturas, en que hablantes y oyentes se refieren, desde el horizonte preinterpretado que su mundo de la vida representa, simultáneamente a algo en el mundo objetivo, en el mundo social y en el mundo subjetivo, para negociar definiciones de la situación que pueden ser compartidas por todos. (pp. 137-138)

La acción comunicativa, precisamente, es una suerte de entendimiento, ya que permite un proceso cooperativo de interpretación. Por supuesto que no se limita solo a eso, sino que, justamente, se abre a la acción. Habermas insiste en que no se debe confundir ni reducir comunicarse e interactuar a simplemente conversar. El entendimiento lingüístico sería, por tanto, "el mecanismo de coordinación de la acción, que ajusta los planes de acción y las actividades teleológicas de los participantes para que puedan construir una interacción" (Habermas, 1987, p. 138). Pero la acción siempre debe estar; y actuar es la relación del sujeto con un mundo simbólico y objetivo. Asimismo, “el actuar comunicativo supone siempre que hay normas válidas a través de las cuales puede justificarse el actuar humano y no solo motivos empíricos de los actores" (Apel, 1999, p. 78). En efecto, todo discurso comunicativo acarrea pretensiones de validez.

No obstante, Apel cree que las acciones comunicativas del mundo vital que refiere Habermas no son suficientes para explicar su fundamento racional, y cree que lograr esto es imprescindible, ya que dichas acciones normativas son el soporte de certeza de la comunicación. Por eso él alude a la pragmática trascendental como modo de fundamentación última, mediante el lenguaje como mediación de toda relación y condición de posibilidad de construcción del discurso. Apel, justamente, pretende realizar una reconstrucción de los tipos de racionalidad para demostrar que la misma razón posee una estructura dialógica. Tanto la racionalidad estratégica como la comunicativa se hayan contenidas de manera complementaria en dicha estructura. De esta manera contribuye a una fundamentación de la identidad como ipseidad, ya que la mencionada estructura dialógica supone las relaciones sujeto-cosujeto, más precisamente, las relaciones que permiten que un sí mismo se pueda entender como otro, debido a que la configuración de la subjetividad es posible en la interacción de los sujetos dentro una determinada comunidad. Evidentemente, estas interrelaciones presentan conflictos de intereses en el ámbito de una racionalidad estratégica, pero las interacciones contienen el diálogo y el acuerdo como sus condiciones de posibilidad. Es por ello que una teoría reconstructiva de la racionalidad tiene como guía el horizonte pragmático-trascendental que conduce toda la reflexión apeliana.

\section{Dialogicidad, historia e ipseidad}

Ya hemos visto que la racionalidad, para Apel, posee un carácter dialógico. Esta es la manera que encuentra para superar su índole metafísica, como así también su mera instrumentalización, sin caer en la negación de la misma. Para poder 
establecer esta dialogicidad distintiva de la razón, vimos que era fundamental la función mediadora del lenguaje a través de la llamada pragmática trascendental. La articulación de estos elementos es lo que constituye la posibilidad de pensar la identidad como ipseidad. De esta forma, la filosofía de Apel desemboca en la necesidad de una fundamentación de la ética, pues una racionalidad dialógica implica de modo inherente la posibilidad de interacciones sociales.

Es realmente absurdo intentar negar el espacio de interacción y acciones concretas dentro de una comunidad. Al mismo tiempo, este ámbito fáctico de acción incluye la supeditación a normas o la normatividad como guía de los actos. Esto sugiere que de un modo u otro los sujetos que interactúan aceptan ciertas pautas como válidas y que también pretenden que su obrar se entienda como verdadero. Es así que Apel reconoce la menesterosidad de una fundamentación última del plano ético. Sin embargo, este carácter de último no es en modo alguno absoluto. Por el contrario, la facticidad y su contingencia, o lo que es lo mismo, la historia, están operando activamente en el planteamiento de una fundamentación última. Esto quiere decir que las normas no se determinan de una vez y para siempre, sino que la verdad es una reconstrucción que, en el caso de Apel, tiene un carácter colectivo. Esto no se encuentra ni siquiera cerca de un relativismo. Justamente, el reconocer la contingencia histórica lleva a poner la mirada sobre otro elemento que permita fundamentar las normas. Este elemento irrebasable es el lenguaje, cuya mediación en toda relación intersubjetiva es lo que determina la dialogicidad de la razón y, de esta forma, el acuerdo sobre las normas y los criterios de validez en una comunidad determinada históricamente.

De esta manera, la validez del pensamiento intersubjetivo tiene el discurso como condición de posibilidad. Este surge "del objetivo común a priori de la formación del consenso sobre las pretensiones de validez que está incluido en el lenguaje como medium del pensamiento intersubjetivamente válido" (Apel, 1999, p. 84; cursiva añadida). Por lo tanto, es necesario ponerse de acuerdo acerca del sentido y verdad (validez) de los actos lingüísticos, pues el discurso es una construcción cooperativa. Este consenso implica la suspensión de intereses particulares estratégicos-teleológicos. Por ello, la fundamentación del discurso argumentativo debe estar, en principio, libre de la carga de la acción. Esto no significa eliminar la praxis como elemento constitutivo del discurso, pues la ética, en última instancia, se resuelve en un plano concreto, en el mundo de la vida; significa simplemente una justificación racional de las pretensiones de validez del discurso. A causa de esto, Apel distingue dos comunidades de comunicación igualmente importantes que se articulan en la determinación de la racionalidad ética: una ideal y otra real o, lo que en otros lugares de su obra llama, respectivamente, una parte A y una parte B de la ética. En definitiva, lo que Apel quiere mostrar es que, en toda comunidad fáctica, real, hay otra presupuesta, en la cual son posibles condiciones ideales de argumentación y de consenso.

Verdad y fundamentación son las exigencias que están operando de manera decisiva en este planteo. En efecto, Apel se da cuenta de que por más radicales 
que pretendan ser las críticas a la racionalidad, no pueden evitar, empero, que en sí mismas haya cierta pretensión de validez. En este sentido, la verdad es prácticamente ineludible, aunque ya no posee un carácter metafísico absoluto, incondicionado e inmutable (lo cual hay que reconocerle como logro a las críticas desenmascaradoras de la razón). Precisamente, para Apel la verdad se construye de manera colectiva. Esto es así porque el lenguaje en el cual se juegan las condiciones de validez y el carácter dialógico de la racionalidad no es de ningún modo privado, sino que pertenece al dominio público, pues "uno solo no puede seguir una regla y lograr validez para su pensamiento" (Apel, 1985, p. 379). Como había demostrado Pierce, los individuos finitos no pueden alcanzar la verdad de manera individual, sino que requieren de una comunidad ilimitada de investigación. Así también, el acuerdo sobre las normas morales de una sociedad no se puede lograr solipsistamente, basados en la autonomía de la voluntad, pues en tal caso entran en conflicto los intereses particulares con los colectivos, el deber con las consecuencias del accionar, impidiendo la conformación de una identidad que incluya la figura del otro. Por ello, Apel critica el abismo que abrió Kant entre el yo-pienso y el reino de los fines o el ámbito concreto experiencial de realización de las máximas morales. Es de esta manera que se hace imperioso la transformación del yo-pienso por un yo-argumento $\mathrm{o}$, mejor aún, un nosotros-argumentamos. Es la argumentación el verdadero $a$ priori que posibilita la fundamentación de normas a través de la formación del consenso. Ella es el elemento irrebasable.

Por eso, todo participante en el discurso debe comprender que la función de este es elaborar soluciones vinculantes para todas las cuestiones imaginables que se puedan plantear en el mundo de la vida. [...] hay que presuponer que, en un discurso filosófico, todos los interlocutores comparten ya siempre con los demás todos los problemas imaginables [...] y, por eso, están interesados a priori en alcanzar soluciones para los problemas que son susceptibles de consenso para todos los miembros de una comunidad ideal e ilimitada de argumentación. (Apel, 1995, pp. 154-155)

De esta manera, Apel considera al sujeto interlocutor virtual, esto es, aquel individuo que no puede suprimir el discurso intersubjetivo. La determinación de normas solo es posible en el ámbito de un discurso argumentativo tendiente al consenso, válido para todos los afectados. La formación del consenso es lo que Apel llama anticipación contrafáctica. Esto quiere decir que toda comunidad históricamente determinada presupone una comunidad ideal, contrafácticamente anticipada, en la cual es posible la formación del consenso. Este a priori funciona, en realidad, como una idea regulativa, pues al tener un carácter universal y necesario, es también formal. Sin embargo, este estadio es insuficiente, porque se ve imposibilitado de incluir las consecuencias del accionar. Por eso, Apel no formula un nuevo imperativo categórico, sino que hace entrar la historia en el proceso de construcción ético. Esto implica que si bien las normas se fundamentan intersubjetivamente, la autonomía de la voluntad se conserva, pues, en última instancia, la fundamentación de normas concretas es delegada sobre 
los individuos afectados, o sobre los grupos, como sería más apropiado decir. No obstante, esto no está librado al arbitrio de conciencias individuales, ya que todos los afectados tienen como presupuesto de su discurso la idea regulativa del consenso. En este sentido, la anticipación contrafáctica de la comunidad ideal de comunicación permite una legitimación de la comunidad real; es, en todo caso, un principio procedimental.

Las decisiones de conciencia individuales y subjetivas [...] se encuentran ahora mediadas a priori por la exigencia de validez intersubjetiva, porque cada individuo acepta de antemano la argumentación pública como explicitación de todos los criterios posibles de validez y, por tanto, también de la formación racional de la voluntad. (Apel, 1985, pp. 404-405)

Ahora bien, como ya hemos referido, la racionalidad ética no se agota en estos presupuestos formales. En efecto, la fundamentación es totalmente estéril, si no se refiere a una praxis concreta. La facticidad, pues, es otro a priori por considerar. Toda comunidad real está determinada por la contingencia de su tiempo y de sus condiciones sociales. Por lo tanto, las normas definitivas que se apliquen ciegamente, en una comunidad son contraproducentes. De este modo, es necesario incluir los conflictos de intereses que se presentan en las diferentes formas de vida socio-cultural. Para lograrlo, el a priori de la comunidad ideal funciona solo como un principio procedimental que permite un marco normativo para la formulación de pautas concretas. Las mismas son las que verdaderamente pueden responder a la situacionalidad específica de una comunidad y las que pueden prever las consecuencias de las decisiones de acción. Por lo tanto, Apel incluye como corolario de su planteo una ética de la responsabilidad. La responsabilidad por las consecuencias implica la necesidad de un actuar estratégico, pues las condiciones sociales, históricas, son únicas. Los sujetos deben tomar decisiones concretas, deben actuar estratégica-teleológicamente. Sin embargo, este actuar no está supeditado a la arbitrariedad, ya que siempre está presente y de manera anticipada el discurso comunicativo. Por lo tanto, el obrar responsable es un principio de complementación entre la racionalidad estratégica y la discursiva. No es posible eludir la historia, como así tampoco la verdad (entendida como pretensiones de validez del discurso). Ambos elementos se articulan en la construcción ética, ambas comunidades comunicativas son imprescindibles. Este es el modo de superar la mera formalidad de un planteo deontológico de la ética, como así también el de una ética de raigambre metafísica que considere como télos la realización plena del ser en un ideal de virtud personal o una utopía social. Asimismo, si cabe hablar de una teleología en la ética de la responsabilidad, esta es la de la conformación de objetivos a largo plazo. Estos serían simplemente principios susceptibles de consenso que los sujetos puedan apoyar, más allá de los sistemas empleados para sostenerlos, los cuales de ningún modo pueden ser rígidos o incondicionados. Esto es así debido a la imposibilidad de planificar la historia. 
El compromiso de colaborar en la realización a largo plazo y aproximativa de las condiciones de aplicación de la ética discursiva no está unido, de ninguna manera, a la expectativa de una revolución mundial y de un reino de la libertad erigido a partir de aquella. (Apel, 1995, p. 184)

En efecto, el curso de la historia no es predecible, pues no se trata de un desarrollo universal, necesario y unitario. Hay una facticidad y condiciones sociales y culturales que están operando en cada comunidad real, y que determinan la socialización e integración de sus individuos. Los sistemas políticos y económicos, por su parte, pueden consolidarse como mecanismos de dominio, lo cual obstruye la posibilidad del compromiso responsable y del consenso intersubjetivo sobre normas. Por eso, los objetivos a largo plazo no suponen la consolidación sistémica de tales mecanismos de manera definitiva, como si pudieran conducir el curso de la historia de modo unívoco. La realización de la comunidad ideal no es una utopía, sino una idea regulativa, que requiere la supresión de las asimetrías sociales para configurar sujetos argumentantes comprometidos en la responsabilidad solidaria. En consecuencia, la dialogicidad de la razón, signada por el factum histórico, abre el horizonte de posibilidad de configuración de la identidad como ipseidad. La identidad no es ya una determinación solipsista del sí mismo, sino que requiere de la figura del otro. De esta manera, el sí mismo puede entenderse como otro, ya que la alteridad no le es extraña. La figura del otro opera en la consolidación de la identidad, porque libera el espacio de desenvolvimiento de la libertad y la responsabilidad. Cada sujeto es histórico y finito, y se encuentra condicionado por una determinada comunidad con su propia formación cultural. El sujeto no escapa a esto, pero tampoco es pasivo. Él mismo contribuye en dicha formación, pues desde el momento en que es miembro de una comunidad se ve obligado a obrar y a incluir a otros en el entramado de sus acciones. Sus intereses entran en conflicto con los de los demás y debe tomar partido en la responsabilidad por las consecuencias de sus decisiones. Al mismo tiempo, como perteneciente a una comunidad lingüística, esto es, como ser mediado por el lenguaje, puede regular sus acciones por medio del consenso logrado sobre la validez de las normas, consenso en el que él mismo participa como sujeto virtual de argumentación. Por tanto, la identidad se construye colectivamente, es ipseidad porque el otro no es una conciencia supeditada a mi ego, sino que es reconocido como determinante de mí mismo, como un elemento inherente cuyas alteraciones modifican mi propio núcleo.

\section{Conclusión}

El problema de la identidad es posible vislumbrarlo a lo largo de toda la historia de la filosofía, ya sea explícita o implícitamente. La cuestión de la ipseidad abre el panorama para diversos análisis y discusiones, pues es inevitable que la figura del otro ejerza un influjo sobre la determinación del sí mismo. El solipsismo metódico de la tradición moderna muestra que la identidad se constituye como mismidad, desplazando al otro de tal constitución, y aunque, en el mejor de los 
casos, el reconocimiento por parte del otro sea necesario para la elevación a una conciencia de sí universal, esto, empero, no deja de ser una función cognoscitiva, que disuelve las individualidades en tanto tales. La filosofía contemporánea, por su parte, ha pretendido reivindicar el ámbito de la pluralidad, intentando abandonar la mera mismidad del sí mismo. De la misma forma, ha desarrollado una fuerte crítica a la racionalidad en tanto noción absoluta. Karl-Otto Apel comparte esta des-absolutización de la razón, pero no así su depotenciación. Por el contrario, quiere recuperar la solidez de la misma y, en consecuencia, plantea que hay que entenderla desde su carácter de dialogicidad.

Hemos visto que en la filosofía de Apel la identidad se constituye como ipseidad y que, en primera instancia, se construye a partir de estructuras formales de la razón. Esto es así debido a la condición dialógica de la subjetividad que sostiene el autor. En efecto, lo que está operando de manera decisiva aquí es el lenguaje. Los sujetos son seres mediados por la función lingüística, la cual posibilita la comunicación entre ellos y, por consiguiente, la posibilidad de la interacción intersubjetiva. Ahora bien, el lenguaje estaría funcionando entonces como una suerte de a priori en las relaciones humanas. Por lo tanto, tiene un carácter formal de universalidad y necesariedad. Asimismo, Apel ha mostrado que en las relaciones discursivas de los sujetos es necesario anticipar un sentido sobre los enunciados. Esta pre-comprensión, que es un acuerdo entre los afectados por el discurso, es una condición indispensable para la comunicación con pretensiones de validez. Por lo tanto, la estructura anticipativa del sentido también es de algún modo formal. De hecho, el espacio donde se articulan estas estructuras es el de la comunidad comunicativa ideal, la cual no es más que una idea regulativa que opera en toda comunidad real de comunicación como su condición de posibilidad. Todas estas consideraciones nos conducen a la conclusión de que la identidad, en tanto ipseidad, es posible reconstruirla, en Apel, a partir de estas estructuras formales. Es decir, su génesis es formal, pero no por ello permanece exclusivamente en este ámbito. El interés apeliano de una fundamentación última está orientado al plano ético, pues es menester poder normativizar el accionar de los hombres en la época de la ciencia, teniendo en cuenta la responsabilidad por las consecuencias del obrar y una cierta emancipación del sujeto en tanto miembro de una comunidad concreta, con derecho a igualdad de condiciones y con la posibilidad de ser un actor efectivo en la formación del consenso sobre las normas que le afectan. Al respecto, Apel formula un nuevo a priori, un tanto sui generis, para la fundamentación última, que es el a priori de la historia. Este factum es ineludible. Toda comunidad real está, en realidad, determinada por sus condiciones peculiares, contingentes y temporales. Del mismo modo, estas condiciones particulares determinan el discurso, pues cada forma de vida configura un juego de lenguaje particular, que es irreductible a otros (si bien Apel aclara que hay, además, un juego trascendental del lenguaje, esto es, la regla lingüística, como condición de posibilidad de todos los demás). Consiguientemente, el plano concreto, la praxis, es indispensable para la configuración de la ipseidad. 
No obstante, el planteo apeliano presenta algunas dificultades. Enrique Dussel, quien, a nivel general, podríamos decir que se encuentra dentro de la misma línea de pensamiento que Apel, esboza algunas críticas contra el planteo de este último (Ibarra Ortiz, 2009). Dussel observa que la comunidad comunicativa apeliana no incluye verdaderamente a todos los miembros de una comunidad como los afectados por el discurso. Existe toda una figura del otro que no está contemplada: la de los marginados, los silenciados. Éstos son, precisamente, los más importantes, pues la ética debe tener un carácter emancipatorio (de liberación, diría el autor). Por lo tanto, la comunidad real no es homogénea. El peligro de esto es que tal comunidad puede convertirse en hegemónica y ejercer el dominio sobre los otros silenciados y excluidos. En este sentido, la facticidad histórica de cada comunidad puede convertirse en una parcialidad en tanto sea la realidad fáctica de un determinado grupo de sujetos y no de la totalidad de los individuos (los marginados), y el discurso estaría tejido por circunstancias que no identifican a todos. Asimismo, para Dussel el consenso de la comunidad comunicativa no sale del ámbito del lenguaje; simplemente es un acuerdo sobre expresiones lingüísticas. Sin embargo, la praxis está por encima del lenguaje y el dominio también puede ejercerse sin el uso del mismo.

El interés de Apel es de algún modo emancipatorio, pues la comunidad comunicativa supone condiciones equitativas de argumentación y la eliminación de las asimetrías dentro de tal comunidad. Sin embargo, él no considera de manera especial el factum de las diferencias de clase. Por lo tanto, su análisis conlleva cierto optimismo en cuanto a las condiciones de conformación del discurso. Es decir, si bien Apel considera que la situación socio-histórica de cada comunidad es un a priori dentro de la fundamentación de normas y, según nuestra perspectiva, determinante en la constitución de la ipseidad, no desarrolla las implicancias que las brechas sociales, las condiciones materiales o la pobreza extrema puedan tener en tal fundamentación. En este sentido, Apel supone que un interlocutor es honesto en la argumentación y que las condiciones del desarrollo del discurso son iguales para todos; pero es evidente que en una sociedad donde los intereses de clase son muy fuertes, semejante optimismo es insuficiente para evitar las pretensiones de reproducción cultural de la clase dominante. De esta manera, coincidiendo con Dussel, al planteo apeliano le falta una suerte de económica que dé cuenta de las condiciones sociales como determinadas por las relaciones económicas de cada comunidad. Esta sería una forma de evitar el peligro de exclusión del otro marginado, y fortalecería la cuestión de la ipseidad.

Por otra parte, la crítica dusseliana respecto a la consideración lingüística de Apel es discutible. Dussel, en verdad, está considerando el lenguaje solo como actos de habla, al decir que el dominio no solo se ejerce por medio de él. Apel, en rigor, no desarrolla mucho la cuestión del lenguaje como actos más allá del habla, pero sigue la misma línea que Peirce con respecto a los signos, como representación de algo para un interpretante. Esto amplía la noción de lenguaje. Además, la comunidad lingüística que forma el consenso lo hace también sobre los signos y su uso e interpretación. De esta manera, el dominio que no 
sea hablado puede ser simbólico. Por lo tanto, es importante que exista una comunidad que interprete las formas simbólicas, pues esto es un gran frente de resistencia contra las arremetidas del poder, siempre y cuando, por supuesto, la comunidad interpretante no sea una hegemónica.

Consiguientemente, una determinación cabal de la ipseidad debe poder resolver la posible brecha entre la comunidad comunicativa ideal y la real. La historia es ineludible y Apel lo sabe. Pero también se da cuenta de que el problema de la verdad (o validez diría él) es asimismo forzoso. Las condiciones materiales tienen un importante influjo en la determinación de la validez de un discurso, y el problema se presenta cuando entran en conflicto la ética de la responsabilidad solidaria con los intereses reproductivos de las clases dominantes, que pueden controlar el discurso mediante el dominio simbólico y la exclusión de los desposeídos y silenciados. Quizás un acercamiento a la filosofía de Foucault podría contribuir al análisis de esta problemática. Lo cierto es que es necesario abrir la cuestión hacia nuevas preguntas sobre las condiciones de posibilidad de configuración de la ipseidad, que brinden herramientas para superar estas dificultades dentro del marco que Apel ha proporcionado para pensarlo.

\section{Referencias}

Apel, K. O. (1985). Transformación de la filosofía. Madrid: Taurus.

Apel, K. O. (1995). Teoría de la verdad y ética del discurso. Barcelona: Paidós.

Apel, K. O. (1999). Estudios éticos. México, D. F.: Fontamara.

Apel, K. O. (2009). Semiótica filosófica. Buenos Aires: Prometeo.

Derrida, J. (1971). De la gramatología. Buenos Aires: Siglo XXI.

Apel, K. O. (1989). Márgenes de la filosofía. Madrid: Cátedra.

Descartes, R. (2004). Discurso del método. Meditaciones metafísicas. La Plata: Terramar. Habermas, J. (1987). Teoría de la acción comunicativa. Madrid: Taurus.

Hegel. G. W. F. (2007). Fenomenología del espíritu. Buenos Aires: FCE.

Heidegger, M. (1999). Ontología. Hermenéutica de la facticidad. Madrid: Alianza.

Husserl, E. (1997). Meditaciones cartesianas. Madrid: Tecnos.

Ibarra Ortiz, H. (2009). Ética y cultura contemporánea. Recuperado de www. robertexto.com/archivo1/etica_cutura.htm\#tope

Jaspers, K. (2003). Nietzsche. Buenos Aires: Sudamericana. 
Kant, I. (1979). Crítica de la razón pura. México, D. F.: Porrúa.

Lyotard, J. F. (1987). La condición posmoderna. Madrid: Cátedra.

Lyotard, J. F. (1996). Moralidades posmodernas. Madrid: Tecnos.

Nietzsche, F. (2007). Más allá del bien y del mal. Buenos Aires: Alianza.

Ricoeur, P. (2006). Sí mismo como otro. Madrid: Siglo XXI.

Sartre, J. P. (2006). El ser y la nada. Buenos Aires: Losada.

Wittgenstein, L. (1988). Investigaciones filosóficas. Barcelona: Crítica. 